\title{
Crop Yield Prediction Using Random Forest Algorithm for Major Cities in Maharashtra State
}

\author{
Kiran Moraye ${ }^{1}$, Aruna Pavate ${ }^{2}$, Suyog Nikam ${ }^{3}$ and Smit Thakkar \\ ${ }^{1,3,4}$ Student, Department of Information Technology, Atharva College of Engineering, Mumbai, Maharashtra, India \\ ${ }^{2}$ Assistant Professor, Department of Information Technology, Atharva College of Engineering, Mumbai, Maharashtra, India
}

Correspondence should be addressed to Kiran Moraye; kiranmoraye11@gmail.com

Copyright () 2021 Made Kiran Moraye et al. This is an open access article distributed under the Creative Commons Attribution License, which permits unrestricted use, distribution, and reproduction in any medium, provided the original work is properly cited.

\begin{abstract}
Maharashtra is a leading State in agriculture. Agriculture is the one that plays important role in the economy of India. India is an agricultural country and its economy largely based upon crop production. Hence one must say that agriculture is often the backbone of all businesses in the a-part-of-us country. Basically paper focuses on predicting the yield of the crop by using a different machine learning algorithm. The application (Smart Farm) developed in this research helps users to predict the crop yield using different climatic parameters. Different methods of predicting crop yield are developed within several years with different outcomes of success, but many of them do not take into consideration the climate. Machine Learning is the best technique which gives a better practical solution to crop yield problem. So the Random Forest algorithm which we decided to used to train our model to give high accuracy and best prediction., we chose 5 climatic parameters to train the model. Agriculture inputs such as pesticides, fertilizers, chemicals, soil quality, etc. were not used as it depends upon the type of field. The model is trained and designed using 20 decision trees build the random forest algorithm which gives better accuracy of the model. 10-fold cross-validation technique used to improve the accuracy of the model. The predicted accuracy of the model is analyzed $87 \%$.
\end{abstract}

KEYWORDS- Climate, crop yield, Indian Agriculture, Machine Learning Techniques, Random Forest Algorithm

\section{INTRODUCTION}

Agriculture is a pivotal sector for ensuring food, sustainable development, nutritional security and elimination of poverty, but recently agriculture in India is fading, all of the problems originating in governmental, constitution structures, and economics. The government supports mostly rice and wheat, with some others throw-in, through factors like "minimum support price". Funding crops is not a strong and healthy system. Agriculture is the broadest economic sector and plays a significant role in the overall socio-economic fabric of India. It contributes to an increase in total GDP and employs over half of the population. Many researchers are aimed at improving agricultural planning and crop productivity with good quality of crops. So our main goal is to get the maximum yield of crops. There are many Machine learning classification techniques are available to get a good quality of yield of crops. So after analysis and comparison of all classification methods, we are choosing the Random Forest classification technique which can be used to improve the yield rate of crops and crop production with crop selection methods. The detailed working of the work is organized as section 2 gives related work with the current work, section 3 concentrates on the Methodology applied, section 4 discusses results and analysis, section 5 concludes the work.

\section{RELATED WORK}

Many researches are tried out to improve good accuracy in agricultural planning. The goal of project is get as possible as better accuracy. There are so many classification methods are also used to give good proportion of crop yield. Machine learning techniques are used to improve the accuracy of crop yield data. There are so many method of crop selection is applied to improve crop production accuracy in past years. This section discusses the previous similar work done attempted by other researchers. Rakesh Kumar et al. [2] concluded this works helps in improving the success of yield rate of crops by applying different classification methods by comparing the different parameters. Various machine learning algorithms compared to predict crop yield. The algorithms included for comparative analysis are Artificial neural network, support vector machine, K-Nearest Neighbors, Decision Tree, Random forest, Gradient boosted decision tree, regularized greedy Forest and proposed CSM technique (Crop Selection Method) which helps in predicting the sequence of crops can be considered for planning in the coming seasons. Author concluded that the prediction is based on many parameters so accuracy and performance of the system varies as per parameters. Jig Han et al. [3] applied random forest algorithm for global and regional crop yield such as potato, maize, wheat and environmental variables such as soil, climate, photoperiod, fertilization data, water. The results compared with multiple linear regressions and evaluated using root mean square, Nash-Sutcliffe model efficiency, index of agreement, observed vs. Predicted plots. The data is considered form different sources in the United states. Results showed Random forest is an effective and dynamic method for crop yield prediction with high accuracy, precision, easy to use and for data analysis. Narayanan Balakrishnan1 et al. [4] proposed ensemble 
model to produce crops over a specific time period using different classification methods studied such as Naive Bayes, support vector machine and proposed new ensemble methods such as AdaSVM, AdaNaive. The proposed model evaluated using accuracy, classification error and concluded with AdaNaive gives best results with accuracy 96.52 for rice crop. Sami Khanal et al. [5] proposed method based on remotely sensed data and machine learning algorithms such as Random forest, Neural Network, Support vector Machine, Gradient boosting model, Cubist to map soil properties and corn yield at a local scale. The data is remotely sensed and model evaluated using root mean square and accuracy. Louis Kouadioa et al. [6] proposed ELM model based on artificial intelligence for coffee yield prediction for small farms instead of using MLR (multiple linear regression) and RF (Random Forest) models. The ELM models compared with various machine learning models. Author claimed that ELM models are more efficient than RF and MLR models in extracting features. There are many supervised machine learning algorithms known as linear regression, Polynomial regression, ecision Tree, Random Forest and Support Vector Machine can be applied to predict the crop yield.

\section{METHODOLOGY}

\section{A. Dataset}

Data plays an important role in Machine Learning. To design and perform crop yield prediction system data is taken from various cities of Maharastra state . As latitude changes from location to location, the data is considered at the district level. Three things are very much needed i.e. Data about the crop, climate of a particular district, and region needed to perform the system. The description of the attributes mentioned in tablel1, table 2 , and table 3 . The data about our project is taken from various districts and regions of Maharashtra and taken from Government Website: www.data.gov.in and for the climate; various districts and regions of Maharashtra is taken from www.imd.gov.in.

Table 1: Attributes from districtwide crop production dataset

\begin{tabular}{|c|c|c|}
\hline $\begin{array}{l}\text { Sr. } \\
\text { No }\end{array}$ & $\begin{array}{c}\text { Attribut } \\
\text { e }\end{array}$ & Description \\
\hline 1. & $\begin{array}{l}\text { District } \\
\text { Name }\end{array}$ & $\begin{array}{l}\text { Total } 27 \text { districts like Ahmednagar, Akola, } \\
\text { Amravati, Aurangabad, Beed, Bhandara, } \\
\text { Chandrapur, Dhule, Gadchiroli, Gondia, } \\
\text { Hingoli, Jalgaon, Jalna, Kolhapur, Latur, } \\
\text { Nanded, Nandurbar, Nashik, Osmanabad, } \\
\text { Parbhani,Pune,Sangli,Satara,Solapur,Ward } \\
\text { ha,Washim,Yavatmal data considered }\end{array}$ \\
\hline 2. & Season & Kharif, Summer, Rabi, Whole Year \\
\hline 3. & Crop & $\begin{array}{l}\text { All type of crops like sunflower, } \\
\text { groundnut, wheat, bajra, jowar, maize etc }\end{array}$ \\
\hline 4. & $\begin{array}{c}\text { Area- } \\
\text { in_hect } \\
\text { or }\end{array}$ & $\begin{array}{l}\text { Area of the farm considered for production } \\
\text { of crop }\end{array}$ \\
\hline
\end{tabular}

Table 2: Sample of District wise crop production data for different cities yearly

\begin{tabular}{|c|c|c|c|c|c|c|c|c|c|c|c|c|c|c|c|c|c|c|c|c|c|}
\hline & A & B & c & D & E & $\mathrm{F}$ & G & H & 1 & J & $k$ & L & M & N & 0 & $\mathrm{P}$ & Q & $\mathrm{R}$ & s & $T$ & U \\
\hline 1 & District__Name & Season & Crop & PSUM(Integer/mn & TSUM(Inte C & CSUM(Inte) & VSUM(IntiV & WSUM/Int & Psummer & Tsummer & Csummer & Vsummer & Wsummer & Pkharif & Tkharif & Ckharif & Vkharif & Wkharif & Prabi & Trabi & Crabi \\
\hline 2 & AHMEDNAGAR & Kharif & Arhar/Tur & 953.641 & 304.15 & 422.135 & 231.092 & 56.5886 & 296.517 & 110.887 & 123.767 & 82.694 & 14.4179 & 545.207 & 102.6 & 223.535 & 93.745 & 36.8803 & 142.297 & 143.333 & 116.553 \\
\hline 3 & AHMEDNAGAR & Kharif & Bajra & 953.641 & 304.15 & 422.135 & 231.092 & 56.5886 & 296.517 & 110.887 & 123.767 & 82.694 & 14.4179 & 545.207 & 102.6 & $5 \quad 223.535$ & 93.745 & 36.8803 & 142.297 & 143.333 & 116.553 \\
\hline 5 & AHMEDNAGAR & Kharif & Jowar & 953.641 & 304.15 & 422.135 & 231.092 & 56.5886 & 296.517 & 110.887 & 123.767 & 82.694 & 14.4179 & 545.207 & 102.6 & 223.535 & 93.745 & 36.8803 & 142.297 & 143.333 & 116.553 \\
\hline 6 & AHMEDNAGAR & Kharif & Maize & 953.641 & 304.15 & 422.135 & 231.092 & 56.5886 & 296.517 & 110.887 & 123.767 & 82.694 & 14.4179 & 545.207 & 102.6 & 223.535 & 93.745 & 36.8803 & 142.297 & 143.333 & 116.553 \\
\hline 7 & AHMEDNAGAR & Kharif & Moong/Green Gr & 953.641 & 304.15 & 422.135 & 231.092 & 56.5886 & 296.517 & 110.887 & 3.767 & 82.694 & 14.4179 & 545.207 & 102.6 & 5223.535 & 93.745 & 36.8803 & 142.297 & 143.333 & 116.553 \\
\hline 8 & AHMEDNAGAR & Kharif & Pulses total & 953.641 & 304.15 & 422.135 & 231.092 & 56.5886 & 296.517 & 110.887 & 123.767 & 82.694 & 14.4179 & 545.207 & 102.6 & 223.535 & 93.745 & 36.8803 & 142.297 & 143.333 & 116.553 \\
\hline 9 & AHMEDNAGAR & Kharif & Ragi & 953.641 & 304.15 & 422.135 & 231.092 & 56.5886 & 296.517 & 0.887 & 3.767 & 82.694 & 14.4179 & 545.207 & 102.6 & 223.535 & 93.745 & 36.8803 & 142.297 & 143.333 & 116.553 \\
\hline 10 & AHMEDNAGAR & Kharif & Rice & 953.641 & 304.15 & 422.135 & 231.092 & 56.5886 & 296.517 & 110.887 & 123.767 & 82.694 & 14.4179 & 545.207 & 102.6 & 5223.535 & 93.745 & 36.8803 & 142.297 & 143.333 & 116.553 \\
\hline 11 & AHMEDNAGAR & Kharif & Sugarcane & 953.641 & 304.15 & 422.135 & 231.092 & 56.5886 & 296.517 & 110.887 & 123.767 & 82.694 & 14.4179 & 545.207 & 102.6 & 223.535 & 93.745 & 36.8803 & 142.297 & 143.333 & 116.553 \\
\hline 12 & AHMEDNAGAR & Kharif & Total fo & 53.641 & 304.15 & 422.135 & 231.092 & 56.5886 & 296.517 & 110.887 & 3.767 & 82.694 & 14.4179 & 545.207 & 102.6 & 223.535 & 93.745 & 36.8803 & 142.297 & 143.333 & 116.553 \\
\hline 13 & AHMEDNAGAR & Kharif & Urad & 953.641 & 304.15 & 422.135 & 231.092 & 56.5886 & 296.517 & 110.887 & 123.767 & 82.694 & 14.4179 & 545.207 & 102.6 & 5223.535 & 93.745 & 36.8803 & 142.297 & 143.333 & 116.553 \\
\hline 14 & AHMEDNAGAR & Rabi & Jowar & 953.641 & 304.15 & 422.135 & 1.092 & 56.5886 & 296.517 & 110.887 & 123.767 & 82.694 & 14.4179 & 545.207 & 102.6 & 223.535 & 93.745 & 36.8803 & 42.297 & 13.333 & 116.553 \\
\hline 15 & AHMEDNAGAR & Rabi & Maize & 953.641 & 304.15 & 422.135 & 231.092 & 56.5886 & 296.517 & 110.887 & 123.767 & 82.694 & 14.4179 & 545.207 & 102.6 & 223.535 & 93.745 & 36.8803 & 142.297 & 143.333 & 116.553 \\
\hline 16 & AHMEDNAGAR & Rabi & Other Rabi pulse: & 953.641 & 304.15 & 422.135 & 231.092 & 56.5886 & 296.517 & 110.887 & 123.767 & 82.694 & 14.4179 & 545.207 & 102.6 & 223.535 & 93.745 & 36.8803 & 142.297 & 13.333 & 116.553 \\
\hline 18 & AHMEDNAGAR & Summer & Maize & 953.641 & 304.15 & 422.135 & 231.092 & 56.5886 & 296.517 & 110.887 & 123.767 & 82.694 & 14.4179 & 545.207 & 102.6 & 5223.535 & 93.745 & 36.8803 & 142.297 & 143.333 & 116.553 \\
\hline 19 & AHMEDNAGAR & Whole Year & Cotton(lint) & 953.641 & 304.15 & 422.135 & 231.092 & 56.5886 & 296.517 & 110.887 & 123.767 & 82.694 & 14.4179 & 545.207 & 102.6 & 223.535 & 93.745 & 36.8803 & 142.297 & 143.333 & 116.553 \\
\hline 20 & AHMEDNAGAR & Kharif & Arhar/Tur & 940.414 & 1.837 & 460.078 & 237.504 & 57.8341 & 111.472 & 117.991 & 125.124 & 88.152 & 9.2211 & 772.879 & 104.475 & 269.267 & 95.666 & 44.6603 & 135.432 & 141.954 & 117.912 \\
\hline 21 & AHMEDNAGAR & Kharif & Bajra & 940.414 & 311.837 & 460.078 & 7.504 & 57.8341 & 111.472 & 117.991 & 125.124 & 88.152 & 9.2211 & 772.879 & 104.475 & 269.267 & 95.666 & 44.6603 & 135.432 & 141.954 & 117.912 \\
\hline 22 & AHMEDNAGAR & Kharif & Castor seed & 940.414 & 311.837 & 460.078 & 237.504 & 57.8341 & 111.472 & 117.991 & 125.124 & 88.152 & 9.2211 & 772.879 & 104.475 & 269.267 & 95.666 & 44.6603 & 135.432 & 141.954 & 117.912 \\
\hline 23 & AHMEDNAGAR & Kharif & Cotton(lint) & 940.414 & 311.837 & 460.078 & 7.504 & 57.8341 & 111.472 & 117.991 & 125.124 & 1.152 & 9.2211 & 772.879 & 104.475 & 269.267 & 95.666 & 44.6603 & 135.432 & 141.954 & 117.912 \\
\hline 24 & AHMEDNAGAR & Kharif & Groundnut & 940.414 & 311.837 & 460.078 & 237.504 & 57.8341 & 111.472 & 117.991 & 125.124 & 88.152 & 9.2211 & 772.879 & 104.475 & 269.267 & 95.666 & 44.6603 & 135.432 & 141.954 & 117.912 \\
\hline 25 & AHMEDNAGAR & Kharif & Jowar & 940.414 & 311.837 & 460.078 & 237.504 & 57.8341 & 111.472 & 117.991 & 125.124 & 88.152 & 9.2211 & 772.879 & 104.475 & 269.267 & 95.666 & 44.6603 & 135.432 & 141.954 & 117.912 \\
\hline 26 & AHMEDNAGAR & Kharif & Maize & 940.414 & 311.837 & 460.078 & 237.504 & 57.8341 & 111.472 & 117.991 & 125.124 & 88.152 & 9.2211 & 772.879 & 104.475 & 269.267 & 95.666 & 44.6603 & 135.432 & 141.954 & 117.912 \\
\hline 27 & AHMEDNAGAR & Kharif & Moong/Green Gr & 940.414 & 311.837 & 460.078 & 237.504 & 57.8341 & 111.472 & 117.991 & 125.124 & 88.152 & 9.2211 & 772.879 & 104.475 & 269.267 & 95.666 & 44.6603 & 135.432 & 141.954 & 117.912 \\
\hline 28 & AHMEDNAGAR & Kharif & Niger seed & 940.414 & 311.837 & 460.078 & 237.504 & 57.8341 & 111.472 & 117.991 & 125.124 & 88.152 & 9.2211 & 772.879 & 104.475 & 269.267 & 95.666 & 44.6603 & 135.432 & 141.954 & 117.912 \\
\hline 29 & AHMEDNAGAR & Kharif & Other Cereals \& & 940.414 & 311.837 & 460.078 & 237.504 & 57.8341 & 111.472 & 117.991 & 125.124 & 88.152 & 9.2211 & 772.879 & 104.475 & $5 \quad 269.267$ & 95.666 & 44.6603 & 135.432 & 141.954 & 117.912 \\
\hline 30 & AHMEDNAGAR & Kharif & Other Kharif puls & 940.414 & 311.837 & 460.078 & 237.504 & 57.8341 & 111.472 & 117.991 & 125.124 & 88.152 & 9.2211 & 772.879 & 104.475 & 5 269.267 & 95.666 & 44.6603 & 135.432 & 141.954 & 117.912 \\
\hline 31 & AHMEDNAGAR & Kharif & Ragi & 940.414 & 311.837 & 460.078 & 237.504 & 57.8341 & 111.472 & 117.991 & 125.124 & 88.152 & 9.2211 & 772.879 & 104.475 & 269.267 & 95.666 & 44.6603 & 135.432 & 141.954 & 117.912 \\
\hline 12 & AHMAENMAFAR & Vharif & Rire & & & & & & & & & & & & & & & & & & \\
\hline
\end{tabular}


Table 3: Sample of Climate dataset

\begin{tabular}{|c|c|c|c|c|c|c|c|c|c|c|c|c|c|}
\hline K & L & M & $\mathrm{N}$ & $\mathrm{O}$ & P & $\mathrm{Q}$ & $\mathrm{R}$ & s & T & u & v & w & $\mathrm{x}$ \\
\hline Csummer & Vsummer & Wsummer & Pkharif & Tkharif & Ckharif & Vkharif & Wkharif & Prabi & Trabi & Crabi & Vrabi & Wrabi & Productic \\
\hline 123.767 & 82.694 & 14.4179 & 545.207 & 102.6 & 223.535 & 93.745 & 36.8803 & 142.297 & 143.333 & 116.553 & 86.978 & 8.8773 & 0.35795 \\
\hline 123.767 & 82.694 & 14.4179 & 545.207 & 102.6 & 223.535 & 93.745 & 36.8803 & 142.297 & 143.333 & 116.553 & 86.978 & 8.8773 & 0.55746 \\
\hline 123.767 & 82.694 & 14.4179 & 545.207 & 102.6 & 223.535 & 93.745 & 36.8803 & 142.297 & 143.333 & 116.553 & 86.978 & 8.8773 & 0.45588 \\
\hline 123.767 & 82.694 & 14.4179 & 545.207 & 102.6 & 223.535 & 93.745 & 36.8803 & 142.297 & 143.333 & 116.553 & 86.978 & 8.8773 & 1.22222 \\
\hline 123.767 & 82.694 & 14.4179 & 545.207 & 102.6 & 223.535 & 93.745 & 36.8803 & 142.297 & 143.333 & 116.553 & 86.978 & 8.8773 & 1.06818 \\
\hline 123.767 & 82.694 & 14.4179 & 545.207 & 102.6 & 223.535 & 93.745 & 36.8803 & 142.297 & 143.333 & 116.553 & 86.978 & 8.8773 & 0.08824 \\
\hline 123.767 & 82.694 & 14.4179 & 545.207 & 102.6 & 223.535 & 93.745 & 36.8803 & 142.297 & 143.333 & 116.553 & 86.978 & 8.8773 & 0.28825 \\
\hline 123.767 & 82.694 & 14.4179 & 545.207 & 102.6 & 223.535 & 93.745 & 36.8803 & 142.297 & 143.333 & 116.553 & 86.978 & 8.8773 & 0.80769 \\
\hline 123.767 & 82.694 & 14.4179 & 545.207 & 102.6 & 223.535 & 93.745 & 36.8803 & 142.297 & 143.333 & 116.553 & 86.978 & 8.8773 & 1.22034 \\
\hline 123.767 & 82.694 & 14.4179 & 545.207 & 102.6 & 223.535 & 93.745 & 36.8803 & 142.297 & 143.333 & 116.553 & 86.978 & 8.8773 & 0.84837 \\
\hline 123.767 & 82.694 & 14.4179 & 545.207 & 102.6 & 223.535 & 93.745 & 36.8803 & 142.297 & 143.333 & 116.553 & 86.978 & 8.8773 & 0.54255 \\
\hline 123.767 & 82.694 & 14.4179 & 545.207 & 102.6 & 223.535 & 93.745 & 36.8803 & 142.297 & 143.333 & 116.553 & 86.978 & 8.8773 & 0.5 \\
\hline 123.767 & 82.694 & 14.4179 & 545.207 & 102.6 & 223.535 & 3.745 & 36.8803 & 142.297 & 143.333 & 116.553 & 86.978 & 8.8773 & 0.36263 \\
\hline 123.767 & 82.694 & 14.4179 & 545.207 & 102.6 & 223.535 & 3.745 & 36.8803 & 142.297 & 143.333 & 116.553 & 86.978 & 8773 & 1.46774 \\
\hline 123.767 & 82.694 & 14.4179 & 545.207 & 02.6 & 223.535 & .745 & 36.8803 & 142.297 & 43.333 & 16.553 & 86.978 & 8773 & 0.05 \\
\hline 123.767 & 82.694 & 14.4179 & 545.207 & 102.6 & 223.535 & 93.745 & 36.8803 & 142.297 & 143.333 & 116.553 & 86.978 & 8.8773 & 1.09285 \\
\hline 123.767 & 82.694 & 14.4179 & 545.207 & 102.6 & 223.535 & 93.745 & 36.8803 & 142.297 & 143.333 & 116.553 & 86.978 & 8.8773 & 1.72727 \\
\hline 123.767 & 82.694 & 14.4179 & 545.207 & 102.6 & 223.535 & 93.745 & 36.8803 & 142.297 & 143.333 & 116.553 & 86.978 & 8.8773 & 182.653 \\
\hline 125.124 & 88.152 & 9.2211 & 772.879 & 104.475 & 269.267 & 95.666 & 44.6603 & 135.432 & 141.954 & 117.912 & 86.255 & 9.8049 & 0.51596 \\
\hline 125.124 & 88.152 & 9.2211 & 772.879 & 104.475 & 269.267 & 95.666 & 44.6603 & 135.432 & 141.954 & 117.912 & 86.255 & 9.8049 & 0.80655 \\
\hline 125.124 & 88.152 & 9.2211 & 772.879 & 104.475 & 269.267 & 95.666 & 44.6603 & 135.432 & 141.954 & 117.912 & 86.255 & 9.8049 & 0.25 \\
\hline 125.124 & 88.152 & 9.2211 & 772.879 & 104.475 & 269.267 & 95.666 & 44.6603 & 135.432 & 141.954 & 117.912 & 86.255 & 9.8049 & 1.64463 \\
\hline 125.124 & 88.152 & 9.2211 & 772.879 & 104.475 & 269.267 & 95.666 & 44.6603 & 135.432 & 141.954 & 117.912 & 86.255 & 9.8049 & 0.87324 \\
\hline 125.124 & 88.152 & 9.2211 & 772.879 & 104.475 & 269.267 & 95.666 & 44.6603 & 135.432 & 141.954 & 117.912 & 86.255 & 9.8049 & 1.66667 \\
\hline 125.124 & 88.152 & 9.2211 & 772.879 & 104.475 & 269.267 & 95.666 & 44.6603 & 135.432 & 141.954 & 117.912 & 86.255 & 9.8049 & 2.15517 \\
\hline 125.124 & 88.152 & 9.2211 & 772.879 & 104.475 & 269.267 & 95.666 & 44.6603 & 135.432 & 141.954 & 117.912 & 86.255 & 9.8049 & 0.58333 \\
\hline 125.124 & 88.152 & 9.2211 & 772.879 & 104.475 & 269.267 & 95.666 & 44.6603 & 135.432 & 141.954 & 117.912 & 86.255 & 9.8049 & 0.42857 \\
\hline 125.124 & 88.152 & 9.2211 & 772.879 & 104.475 & 269.267 & 95.666 & 44.6603 & 135.432 & 141.954 & 117.912 & 86.255 & 9.8049 & 0.58537 \\
\hline 125.124 & 88.152 & 9.2211 & 772.879 & 104.475 & 59.267 & .666 & 44.6603 & 135.432 & 954 & 117.912 & 86.255 & .8049 & 0.41667 \\
\hline 25.124 & 88.152 & 2211 & 772.879 & 4.475 & 269.267 & 5.666 & 44.6603 & 135.432 & 41.954 & 117.912 & 86.255 & 9.8049 & 7 \\
\hline 135131 & 28157 & a 2311 & 1778 רד & 101175 & 260267 & o5 אKא & $11 \mathrm{~K} 6 \cap 2$ & $125 \quad 127$ & 111 a5 & 117017 & 26255 & a enıa & 123112 \\
\hline
\end{tabular}

\section{B. Proposed System}

Random forest is a basically supervised learning algorithm that is used for both classifications as well as regression. Random forest algorithm creates decision trees on different data samples and then predict the data from each subset and then by voting gives better the solution for the system. Random Forest used the bagging method to trained the data. Basically, the bagging method is a mixture of studying different models and increase the final result of the system.

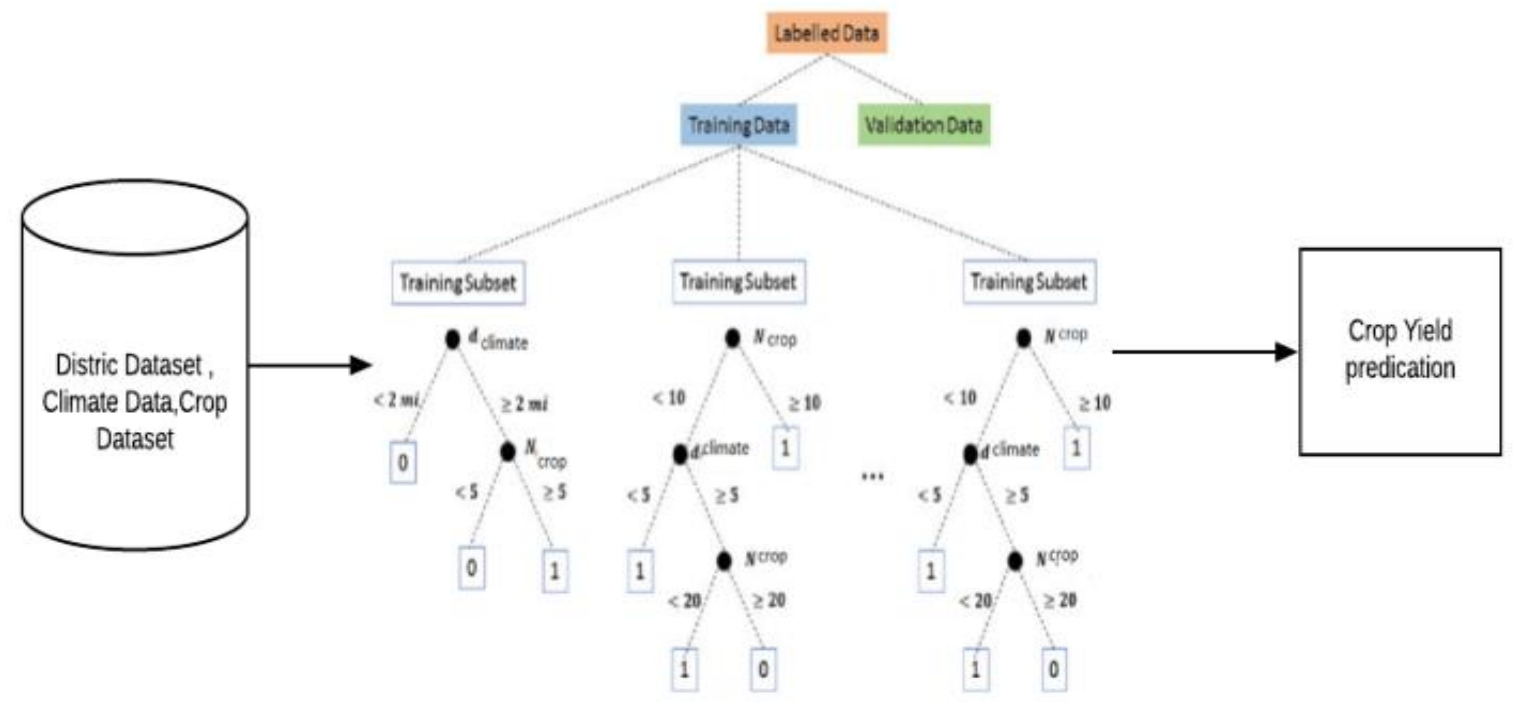

Fig. 1: Proposed block diagram for crop yield prediction

For getting high accuracy we used the Random Forest algorithm which gives accuracy which predicate by model and actual outcome of predication in the dataset. In the random forest which crates the decision tree from a sample of data and trees gives the prediction from each family and selects the best solution by voting which gives better accuracy for the model. It gives optimum results for the system.

Pseudocode of the Proposed System:

1. In this basically we first randomly selected the $\mathrm{k}$ to feature out of the total $\mathrm{m}$ feature in the model.

2. Using the best split point choose the $\mathrm{k}$ feature and calculate the node $\mathrm{d}$. 
3. So we used the split method, split the nodes into the daughter node.

4. Repeat 1 to three steps until 1 number of nodes has been reached

5. Build forest by repeating steps 1 to 4 for $n$ number times to make $\mathrm{n}$ number of trees.

To perform prediction using the trained random forest algorithm uses the below pseudocode:

1. In this, we took the test features and every random decision tree to predicate the output and anticipated the outcome which is stored

2. And then we calculated the vote which is given by every decision tree for each predicated outcome.

3. Finally, we considered high voted predicated outcome which gives the final prediction from the random forest algorithm.

\section{RESULT AND ANALYSIS}

The goal of our project is to build a user-friendly web application which will help the farmers, user and more policy planners to predict the crop yield based on the factor of climate change. so a web application named 'Smart Farm' is developed.

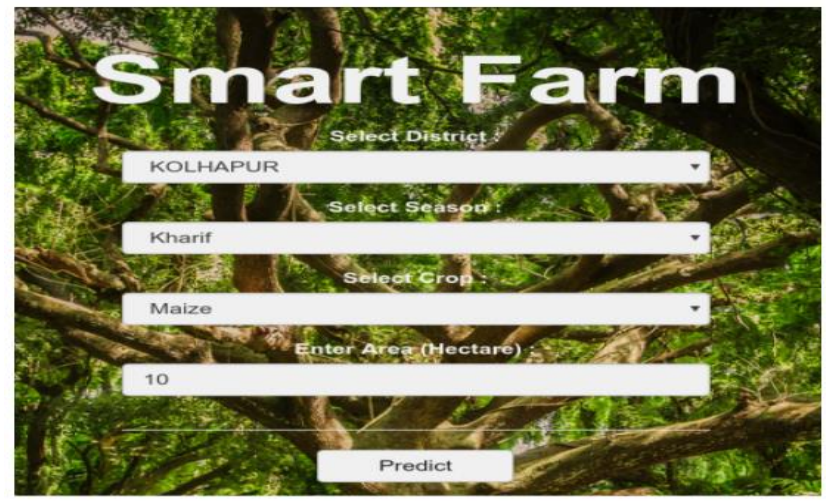

Fig. 2: User Interface: Homepage

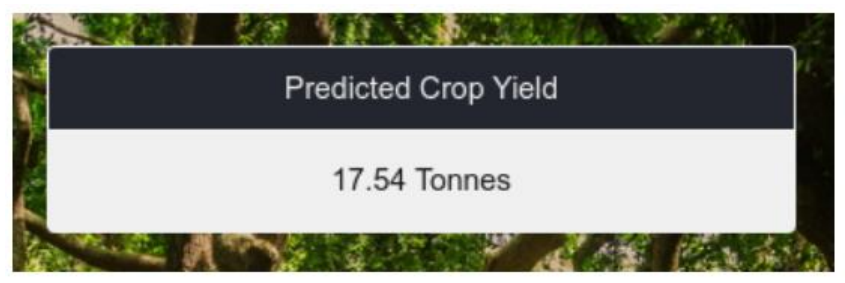

Fig. 3: Predicted result after selecting different parameters by the user like district, season, type of crop and Area in Hectare

We decided that our system is designed using python and flask framework was used to render the results into a web page. As shown in figure 2, User and Farmers of the application can see the home page and will able to enter the details such as the district name, season, crop name and area of respective user's field (in hectare). Once mandatory details are filled on the home page user press the predicate button then the request will send toward the server and the system gives a prediction using the model and trained under the random forest algorithm. Figure 3 shows, the result of the prediction of the crop yield which is sent to the respective user and the unit of the crop yield is considered in tones.

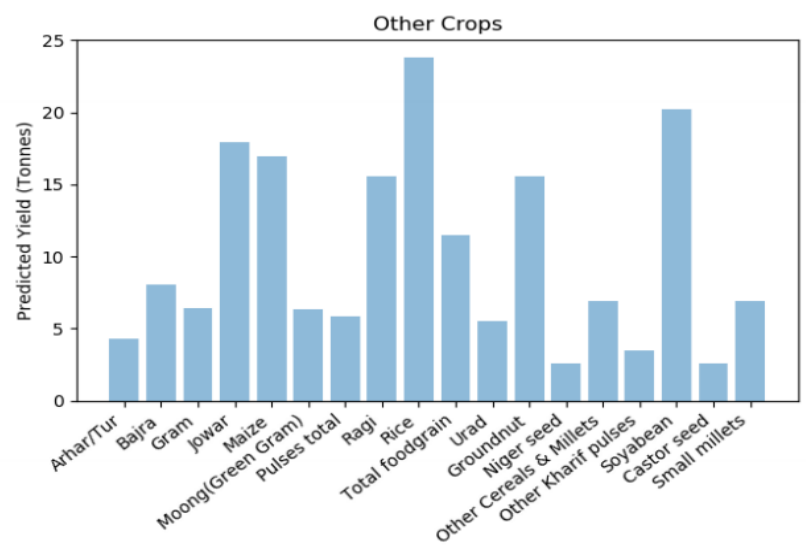

Fig. 4: Graphical representation of the Type of crop vs. predicted yield

The result page of the Smart Farm application, also displays a graph of Crops that farmers can plant in his district vs. yield the respective crop will produce. As shown in figure 4, the graph is suggesting which crops could be planted in the Kolhapur district vs. their respective yield. and you can see in the figure, In Kharif, season rice could be planted in the Kolhapur district which gives more yield than Maize. This will help the user to conclude which crop he could plant to get a better yield.

\section{$[0,945213090,0.839396070,0971741520,9548399550,51812120550,97285024$ $0.655501330 .8933999630 .934520870 .98442227]$ Accuracy; $0.87(+1 \cdot 0.15)$}

Fig. 5: Performance evaluation of the system using metric Accuracy

In this model we trained 20 decision trees to build a random forest. In our project, we used a 10-fold crossvalidation technique which gives the accuracy of the required model (as shown in figure 5), the accuracy of the model achieved $87 \%$.

\section{CONCLUSION}

In this model we used 10 -fold cross-validation technique which is indicates which is gives high accuracy and correlation between the climate and the crop yield and accuracy of the model is found $87 \%$. In our Project, other factors like quality of soil, pest, chemicals which is used, etc. were not used as it depends upon the type of field. As the climate has changed with the season it is very difficult for farmers, so our web application will help farmers and users to take a better decision according to climate of particular season to decide which crop need to plant-based on which climate. It will also help policy planners to import-export, pricing, marketing, etc to take the best decision even before the crop is harvested. 


\section{REFERENCES}

[1]. Aruvansh Nigam,Saksham Garg,Archit Agrawa,*Parul Agrawal,Crop Yield Prediction Using Machine Learning Algorithms",2019 Fifth International Conference on Image Information Processing (ICIIP),pp 125-130

[2]. Rakesh Kumar1, M.P. Singh2, Prabhat Kumar3 and J.P. Singh4,"2015 International Conference on Smart Technologies and Management for Computing, Communication, Controls, Energy and Materials (ICSTM), Vel Tech Rangarajan Dr. Sagunthala R\&D Institute of Science and Technology, Chennai, T.N., India. 6 - 8 May 2015. pp.138-145.

[3]. Jeong JH, Resop JP, Mueller ND, FleisherDH, Yun K, Butler EE, et al. (2016)"Random Forests for Global and Regional Crop Yield Predictions" ,PLoSONE 11(6): e0156571. doi:10.1371/journal.ppone.0156571 pp-1-15

[4]. Narayanan Balakrishnan1 and Dr. Govindarajan Muthukumarasamy2,"Crop Production-Ensemble Machine Learning Model for Prediction",International Journal of Computer Science and Software Engineering (IJCSSE), Volume 5, Issue 7, July 2016 ISSN (Online): 2409-4285 www.IJCSSE.org Page: 148-153

[5]. Sami Khanala,*John Fultonb,Andrew Klopfensteinb,Nathan Douridasc,Scott Shearerb,"Integration of high resolution remotely sensed data and machine learning

[6]. techniques for spatial prediction of soil properties and corn yield",Computers and Electronics in Agriculture Volume 153, October 2018, Pages 213-225

[7]. Louis Kouadioa, $*$ Ravinesh C. Deob, $*$ Vivekananda Byrareddya,Jan F. Adamowskic,Shahbaz Mushtaqa,Van Phuong Nguyend,"Artificial intelligence approach for the prediction of Robusta coffee yield using soil fertility properties",Computers and Electronics in Agriculture Volume 155, December 2018, Pages 324-338

\section{ABOUT THE AUTHORS}

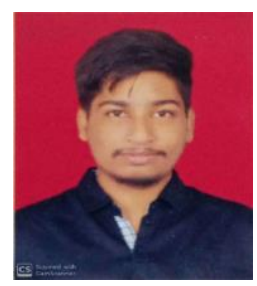

Kiran Moraye is currently a final year student who is pursuing Bachelor of Engineering degree in Information Technology from Mumbai University. His research interests include data analytics and machine learning with application crop yield production.

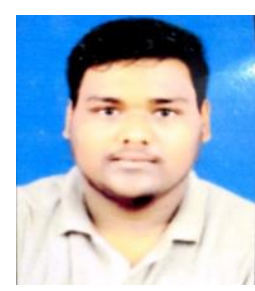

Suyog Nikam is currently a final year student who is pursuing Bachelor of Engineering degree in Information Technology from Mumbai University. His research interests include Android Development and Data Analytics.

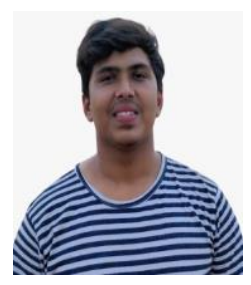

Smit Thakkar is currently a final year student who is pursuing Bachelor of Engineering degree in Information Technology from Mumbai University. His research interests include UI/UX , web development and machine learning .

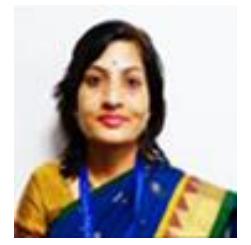

Aruna Pavate pursuing her Research in Information Technology from Mumbai University and working as an Assistant Professor at Atharva college of Engineering, Mumbai, India. Currently working on new advances in the field of medical and engineering to improve in the health care domain. Her research interests include Machine learning and security, data mining, Data Science. She also spent few years working in the industry. She has over 40 peer reviewed articles. She is an editorial board member, reviewer for Science publishing group 2020, and Guest editor of special Issue on Advanced deep learning methods for Audio and Speech Processing. She had worked as reviewer for Journal American Journal Experts (AJE) as well as worked as reviewer for many conferences. She had been Program Chair for IFERP Unit of VVERT Conference 2015 \& 2016, Mumbai India. She is having member of professional bodies ISTE, IAENG, AICTSD,Insc 